\title{
Natural Metaphor and Cognition in Virginia Woolf's Ecological Novels
}

\author{
Wei Ding \\ Department of Humanities and Social Sciences, Heilongjiang Bayi Agricultural University, Daqing, China \\ Email: dingwei0508@gmail.com
}

How to cite this paper: Ding, W. (2020). Natural Metaphor and Cognition in Virginia Woolf's Ecological Novels. Advances in Literary Study, 8, 46-57. https://doi.org/10.4236/als.2020.82005

Received: January 14, 2020

Accepted: March 23, 2020

Published: March 26, 2020

Copyright $\odot 2020$ by author(s) and Scientific Research Publishing Inc. This work is licensed under the Creative Commons Attribution International License (CC BY 4.0).

http://creativecommons.org/licenses/by/4.0/

\begin{abstract}
Animal images are important components in Virginia Woolf's ecological novels, which are part of natural metaphor. This thesis is an exploration of the process of the cognition in Woolf's literary creation through the analysis of the usage of the metaphorical images in her novels. Two major animal images-snail and moth-are examined following a biographical study, which can contribute to exploring Woolf's ecological consciousness and the adoption of her concepts in her ecological writing.
\end{abstract}

\section{Keywords}

Natural Metaphor, Cognition, Virginia Woolf, Ecological Novels

\section{Introduction}

The word "imagery" has been endowed with rich connotations in the history of literary theory. This concept, like other concepts in ancient Chinese literary theory, has no clear meaning or usage of any one meaning. The two concepts of "meaning" and "image", originally two independent concepts, originated in the pre-Qin and Six Dynasties, are two concepts in ancient Chinese literary theory. It was used in literature. Wang Chong of Han Dynasty first combined "meaning" and "image" into one word, and mentioned "the image of ceremony and its precious value". At this time, "imagery" has a dual structure of representation and meaning. Influenced by Chinese and Western classical imagery theories, modern scholars have different understandings of the word "imagery". Imagery is an objective image combined with subjective emotion, or the subjective emotion expressed by objective things. The concept of imagery has been broadened and equated with an artistic image.

Images can express the author's thoughts and aesthetic emotions in different forms; "animal image" refers to the aesthetic images that express the author's 
thoughts and feelings with animals as the carrier. Psychologically speaking, fish represents wealth. As birds do not rely on any tangible things, but on invisible wind to fly in the air, it represents freedom. There is very soft meat in the shell of shellfish with hard shell as a self-defense mechanism. Therefore, shellfish often represent the characteristics of self-protection. Likewise, it symbolizes those who want to protect themselves, because they are sensitive and vulnerable. As the use of animal images in literature can express the author's feelings in more detail, Woolf uses various animals as carriers to express herself.

There are many reasons why Woolf is good at using animal images, and one of the prominent reasons is the influence of the family. Woolf was very happy in childhood, and her father liked her very much. Her father was a writer, under the influence of whom, Woolf also read many books. For example, in 1883, when Virginia was nearly two years old, he wrote that every time he read Bewick's book (a book about birds), she would sit on his lap and lean her face on his face and asked for a kiss. A few months later, he wrote that she was very happy, pressed her small body tightly to me, and then raised her head with bright eyes through her shiny hair and said, "Daddy, don't go!" "She always looks naughty; I've never seen such a little naughty ghost” (Bell, 1972). But happiness is always short-lived. The successive deaths of mother, sister, and father end this happiness forever. Her happy childhood instantly went into darkness, and she could no longer see the light again. Like moths, they live in a humid and dark environment from a little sunshine at birth to the end of life. Therefore, it is appropriate to describe the life of Woolf with the life of a moth.

Another possible source is the moth, which remains at the heart of Virginia Woolf's childhood. Her sister Vanessa's name symbolizes a genus of butterflies, which Virginia Woolf clearly knows. In her works, she mentions several butterflies, which belong to the Vanessa butterfly species. It's no surprise that Vanessa has a butterfly of her own, and Woolf uses the image of her nocturnal brother moth. Like Woolfs dreamed pupa, she first lived in happiness, then in darkness. The transformation from pupa to moth requires energy, which is difficult to describe. The essence of real life is energy. Woolf regarded herself as a moth, "a line of light of life", which existed for a short time until it faced the strange and miraculous death. For Virginia Woolf, the moth in Victorian literature began the process of self connection with her memory and writing.

\section{Natural Metaphor and Cognition on Male and Female Relationship}

In biology, androgyny refers to having mature male organs and mature female organs in the same body. From the point of view of body structure and physiological characteristics, the mixture of men and women has been highlighted. In psychology, androgyny refers to the same body with obvious male personality characteristics, but also has obvious female personality characteristics, which are both strong and weak, decisive and cautious, and make different performance 
according to the situation. As a literary critic and writer, Woolf put forward the idea of "androgyny" in A Room of One's Own in 1929, which is the result of her long-term thinking. But in fact, this idea has been reflected in the early works The Mark on the Wall, which has been fully represented in the image of snail.

Woolf's family environment and experience make it possible for Woolf to think about gender issues. Therefore, in the face of such a social and historical situation, Woolf tried to explore ways to solve the problem of gender inequality, that is, Woolf's "androgyny" thought. Woolf wrote in the opening paragraph of The Mark on the Wall, "The mark was a small round mark, black upon the white wall, about six or seven inches above the mantelpiece" (Woolf, 2015). The small black and round mark on the white wall and the big white and square wall form a distinct binary opposition, which is consistent with the binary opposition of male and female view rooted in the society at that time. The author's consciousness has gone through the process from "nail", "rose" to "tomb or camp", "crack on wooden board" to "snail", but why the mark on the wall is not the image mentioned above but the snail, in essence, the author believes that it stems from the hermaphrodite nature of the snail, which implies Woolf's androgyny. Specifically, the snail has two different characteristics: female and male.

In her book $A$ Room of One's own (1929), Woolf borrows the view of the poet Samuel Taylor Coleridge (1772-1834). He believes that a great brain is always half female and half male. If it is male, then the part of his brain that is female must also have an impact. A woman has to deal with the male part inside her. Woolf thus put forward the idea of androgyny, which shows that "everyone has two kinds of force to control everything, one is male power, the other is female power" (Wu, 2005). The most normal and comfortable situation is that the two forces live in harmony and cooperate in spiritually. This kind of thinking broke through the traditional idea of the opposition between men and women at that time, and expressed Woolf's desire for the harmonious unity of men and women. Snail is the perfect embodiment of this ideal of harmony.

For men, the story of retired colonel in The Mark on the Wall is impressive. From the author's description, we can see a tragic story modeled on male thinking: a man who has spent most of his life fighting in the battlefield, fortunately living in the world, successfully retired in the name of Colonel, and then became an "antique collector", after just preparing to read his article, he suddenly suffered a stroke. At the last sober moment, he saw camp and arrow shovels, not his wife and children. When men are ruled by pure masculinity and pursue fame throughout their lives, they are doers and competitors, who are completely rational and have no time to appreciate the beauty of nature or the love of family life. This morbid passion for aggression, competition and possession is a tragedy for men to abandon women's brains; it is a sorrow both for men and women at the same time. Woolf put forward "contempt", that is, "doers who don't love thinking", and called on men to dare to cultivate women's mentality, experience the joy of leaping thinking like women, and add some "natural tricks". When 
dominated by a single female or male thinking, the androgynous snail on the wall can transform the anxiety and pain, and lead to calmness and happiness. The story of the retired colonel shows the consequences of overindulging on one side of the male thinking, and Woolf shows us an example of the positive pursuit of integrity. Woolf once said, "no one who wants to write and think about his gender can be redeemed" ( $\mathrm{Wu}, 2005)$. In the story, the author forgets about the gender. The first person narrator "I" strongly describes a series of views on nature and civilization, women's dilemma and male hegemony, war and peace. She seems to forget the passive, weak and submissive female characteristics and brave, strong and energetic male characteristics formed by the patriarchal society that has existed for a long time. However, the reality always reminds her that "I am not a very competent housekeeper", "they look at the dust on my fireplace, laugh at me", and say "Troy is a solid tomb composed of three layers of dust, which is not hard to imagine." There are many people who are dominated by single male thinking or female thinking. Obviously, Woolf is not such an image. Woolf is a new woman with male thinking, and a strong woman who demands the harmonious unity of men and women in a patriarchal society. In The Mark on the Wall, Woolf imagined a world without professors and experts, police, absolute knowledge, valueless norms, and not all things have certain rules. Although it seems that such a world is not compatible with the ideal world in the eyes of readers, as the author explains, only in such a world can people's thoughts flow freely. Therefore, the author criticizes a society in which everything is ruled by men, in which life is dominated by men's views. In other words, this is a male power society with female aphasia, a society with extreme imbalance between male and female. In this society, it is difficult for men and women to achieve all-round development. Therefore, as a kind of androgynous animal, the image of snail conveys Woolf's philosophy of dual homogeneity. While criticizing the existing patriarchal society, she calls on both sexes and the whole society to jointly pursue the integrity.

Feminism originated in the West and is a social theory and political movement that uses female experience as the source and motivation. The term feminism first appeared in France, meaning the liberation of women, then spread to Britain and the United States, and gradually became popular. Virginia Woolf is not only a stream-of-consciousness writer, but also a well-known feminist thinker. Her feminist consciousness stems from the unequal treatment she received in her early years. In the Victorian era where Woolf lived, the social customs at that time seemed somewhat similar to the feudal society in China. Only boys could go out of the house and receive formal education, while girls married to serve their husbands, raise their children, and become "Angel" in the house, this is a very important social phenomenon. They don't deserve to receive education. These things in the early years had a great impact on Woolf's life, so she developed a feminist consciousness.

In all her works, we can see the shadow of feminism, which has always occu- 
pied her mind. Woolf uses the image of snail to reflect the most profound feminism in The Mark on the Wall. A snail has a "shell" on its back from birth, and the small "shell" gradually increases with age until death can reduce the burden. If a snail wants to get rid of its heavy "shell" in the process of growing up, it has to find another protective shell to let it settle down, but it can't find it. In a patriarchal society, women grow up under the eaves of male power from birth. In childhood, the relative concealment of gender characteristics let them get a relatively fair treatment. Once gender awareness takes root, differential treatment is inevitable. At this time, for women, the stronger the female consciousness is, the greater the power men exert on them. When women want to get rid of the "eaves" of male power and find their own room, their inner pursuit of freedom and the reality of their own oppression cannot find a way out in the continuous struggle. What lies before them is only the tragic end. The snail carrying a heavy "shell" and the women living under the "eaves" of patriarchal society have a surprisingly similar growth track and inevitable fate. In The Mark on the Wall, the author makes it clear that she wants to have a private space where she wants to stay away from certain facts on the surface, so as to enter a deeper level where she "can think leisurely, quietly and undisturbed, without starting from the chair, without any objection or hindrance, it is easy to think of it" (Woolf, 1919). As a new woman of the times, Woolf's hostility and obstruction in the process of pursuing women's freedom and equal rights are conceivable. Therefore, in the original text of the above sentence, the author has a strong and firm attitude, which shows the author's inner desire for rights and freedom. Twelve years after The Mark on the Wall was published, Woolf's another work, A Room of One's Own attracted public attention. In this feminist work, the author made it clear that a woman must have money to write a novel and need a room of her own. The "room" is a symbol of getting rid of patriarchal rule, a symbol of escaping from the eaves of male rule, a revolt against the tragic fate of women under the shadow of male power, and a manifesto of "new women" represented by Woolf after the first wave and before the second wave of feminism. In other words, this "room" represents a woman's pursuit of freedom and the dispelling of male power. Then the author compares her situation with Shakespeare's. "He sat steadily in his armchair, watching the fire, and a stormy thought came into his mind from heaven" (Woolf, 2004). The author seems to be accusing: if a woman can enjoy freedom and power, have her own room, enjoy the pleasure of thinking and burst out inspiration like a man in Shakespeare's era, then the great female writers who can be recorded in history should be far from the present. However, this can only be a hypothesis. In Female Shakespeare, Woolf imagined the tragic story of Shakespeare's sister Judith. Both the sister and brother have the same origin and ability, but she can't go to school with her brother just because of gender, so she is called to mend socks, cook at home and read at the same time, because she is obsessed with books and is hard to quit. When she refused to be arranged for marriage, her father's firm attitude forced her to run away from home. With the same passion for drama as her brother, she came to 
London to make a living but was laughed at everywhere. When a hypocrite made her pregnant, she finally committed suicide one winter night. When "the poet's heart" is trapped in "the woman's body", and the feminists live under the male eaves, their fate is like a snail carrying a heavy "shell", unable to break free from the shackles and unable to survive.

In Woolf's female consciousness, "I" is the most important concept. The essence of this concept is to make women self-reliant and maintain a good relationship with independent men to achieve mutual promotion. Throughout her life, Woolf has carried forward the female subject consciousness, advocated the harmonious coexistence of men and women, and worked together to criticize the oppression of patriarchal culture on women through writing. This is the goal of her literary creation and literary criticism.

\section{Natural Metaphor and Cognition on Relationship between Man and Nature}

The beauty of natural harmony is also an important theme in Woolf's novels. In the age of Woolf, modern people witnessed the disasters brought by industrial civilization to human macro ecology and micro ecology. Especially after the first World War, western society is full of fear, loneliness and nothingness, and people have encountered unprecedented spiritual crisis. Woolf is also inevitably influenced by the social and cultural background. In this context, she inevitably reflects the spiritual and ecological crisis people faced at that time, as well as the importance of natural harmony.

This is reflected in her short story Kew Garden. The plot of this novel can be considered to have lost the plot of the traditional novel narrative. There is no plot development such as the beginning, development, climax and ending, no clear presentation of the time context, and no full characterization. The novel opens in front of readers a wonderful oval flower bed. Then four groups of people walk through the flower bed at will: the first group is a couple immersed in the past life and their two children; the second group is two men, a young man, an old man with obvious psychological problems, mumbling ambiguous words; the third group is two middle-class people from the lower class; the fourth group is a pair of intimate lovers, but the conversation is ambiguous, even confusing. Four groups of characters are isolated from each other at the edge of the flower bed, which inevitably gives the novel a sense of fragmentation. But besides these four groups of characters, Woolf arranged a calm observer and narrator, a small snail in the flower bed. If the characters in the story come and go, without giving the works a holistic feature, then the snail is an important clue between these characters, turning the fragments into an organic whole, and the snail also has profound symbolic significance. The four groups of characters are irrelevant to each other, as if it were a four-piece patchwork of dynamic clips, taken randomly with Kew Garden as the static background. And at the same time, there is no normal emotional communication between the same pair of characters. Weak 
and reckless language has become the most superficial tool for people to spend time, rather than an effective way of communication. The first couple didn't speak, but each of them had an idea. The man recalled his proposal here 15 years ago and clearly remembered his girlfriend's shoes. The dragonfly flew around two people, and the woman was thinking of a gentle kiss. The second group of characters shows a very discordant feeling: the old man's behavior is strange and seems to be a little confused, "walk high-foot low foot, shaking hard, that to the front of the hands, jerked up the appearance, very much like an impatient pull big horse, in front of the house waiting impatiently..." (Woolf, 2015). He talked for a while about death and heaven, about war and lightning, and about his battery. Young people can't understand the old people's chaotic world of consciousness. Sometimes it takes a long time to react, sometimes they just keep silent. The dialogue between the two women in the third group is a series of repeated and patchwork words, "Nair, Burt, Luo, Sass, Phil, Dad, he said, I said, she said, I said, I said..." (Woolf, 2015). Another example is "My Burt, sister, Bill, Grandpa, that old man, sugar, sugar, flour, salmon, vegetables, sugar, sugar, sugar..." (Woolf, 2015). Not only the readers don't understand the meaning of these words, but also the fat women in the story are confused. They just enjoy the flowers and fall into their own meditation. The last couple seems to be the most harmonious in this group. At least they have a question to answer in their conversation, but it's also confusing and hard to understand to think about their conversation. "Lucky, it's not Friday, said the man. What? Do you believe in luck, too? You'll have to pay six pence in Friday. What does six pence count? That's not worth six pence? What do you mean that? The word 'that' means, what does mean? Ah, just talk about it. I mean ... I mean, you're not going to get it?" (Woolf, 2015).

In short, the four groups of characters Woolf presents are almost included in all kinds of social relations, including men and women, old and young, family, friends, same-sex, heterosexuality, but their communication is not the same. It is full of ineffectiveness, obstacles and misunderstandings, but the inharmonious, alienated and self-centered human society is vividly displayed. It is the snail and the natural environment that form a strong contrast with the human world, which is also reflected in the lack of harmonious relationship within the story. At the beginning of the story, the author presents us a gorgeous and vivid picture: oval flower bed, heart-shaped petals, red blue yellow luster, gentle breeze, brown soil, smooth pebbles, silver raindrops, and brown spiral of snail shell. There are light, distance, stillness, depth, shallowness, greatness and smallness. Woolf's description of natural scenery is full of magic, leaving readers plenty of imagination space in vision, smell and even hearing. When we put down the mundane chores to taste and listen, what we see is no longer black and white, but like a peach blossom swaying like a breeze, with pleasant flowers.

The spirit of exploration is an important symbol of the moth metaphor. The origin of moth imagery can be found in many butterfly and moth expeditions 
written by Quentin Bell in the biography of Virginia Woolf. He described Stephen's children collecting butterflies and moths and categorizing them, and then the image of "moths" began to appear in Virginia's works. Although it has been many years since the moth was captured to create her works, moths are still very important to her. For young Virginia, moth catching may reflect a sense of exploration, excitement, and penetration into unknown territory. Just as the image of the "moth" in her novel The Voyage Out portrays her spirit of adventure, and in her other works, she once wrote: "how did the writer start". All of them express Woolf's deep understanding of life and writing.

Woolf published her first novel The Voyage Out in 1915, when she was 33 years old. However, her novel life began from her thinking about the theme of the novel eight years ago. At that moment, she began to find the inner strength for her title, which was a creative journey, because she created the novel in this experience. Woolf once said that many writers, especially female writers, use their works as a tool for confessing autobiography. If this is true, Virginia's first novel seems to be more compelling, because when she wrote it, she lived in a kitchen belonging to women, and in her fragile state of mind, she needed spiritual support. In this fictional work, moths play an important role. Virginia adds many details and materials to the novel, such as early loss of mother, failure of marriage, experience of death and disease. In this novel, Rachel can be seen as the shadow of Virginia. They have something in common with each other and have the spirit of moth. Rachel's death experience is closely related to that of Virginia. The death of the characters in the novel is astonishing, just as Virginia experienced four sudden deaths of her closest family members when she was young. Her mother died in 1895, her sister Stella in 1897, her father in 1904, and her brother Toby at the age of 26 . These tragedies had a great impact on Woolf. She is like a new moth, self-restraint. In her diary, she said she was on the fifth and that her life had changed a lot in the past few years. It was an important moment for her: she decided to become a writer and married Leonard Woolf, who had experienced much depression, breakdowns and so on. In her diary, she also mentioned the moth in this stage, expressing the emotion of spirit of exploration. Woolf described her mental state to March Wahn, "what I feel now is that there is no love, no passion, no sex dream. What I really care about is to discover the interesting things in the world" (Woolf, 1954). At this stage, the moth represents all the spirit of Woolf, which gives her support and hope, and is the direction of her life. As the text says, "the moth, is a gray wing, shiny breasts, whistling over their heads, banging on the lights now" (Woolf, 2003). But they have to accept the process of life and death, which is an inescapable reality. The spirit of exploration is the process of self discovery, during which, Virginia Woolf established contact with family members, especially her brother Toby. At the same time, in the process of exploration, moths have to face the fate. After Rachel's death, moths appear at the end of her novel. "Someone should have killed it! A young woman put down her needlework and shouted, Poor fellow! It would be kinder to kill it" (Woolf, 2003). The moth image in Woolf's novels is 
considered to be her own, and the moth transformation is obtained from her painful creation process, just as after the tragedy, a new self emerges.

The moth image reveals the intention of Woolf's creation and its relationship with the author. In some ways, Rachel's journey to self discovery seems to be Virginia Woolf's journey in life. In other words, Rachel's journey is a reflection of Virginia's life experience from 1907 to 1915. In addition, Virginia has fantasized about flying with moths since she was very young. In her works and diary, the spirit and form of exploration seem to reflect Woolfs own pursuit. Moths symbolize the rebirth after death. In The Voyage Out, Rachel's death should not only be regarded as death, but also as a positive process of rebirth of a new self.

\section{Natural Metaphor and Cognition on Relationship between Man and Society}

The little snail contains great wisdom. It can not only symbolize androgyny and feminism, but also the positive meaning of life. Woolf created this symbol of the garden in her work Kew Garden. The four groups of characters in the story vividly reflect the loneliness in the background of highly materialized society and the huge obstacle of emotional communication among people. The modern capitalist society is becoming more and more commercialized and materialistic, so people's ability, wisdom and fraternity are more and more needed to balance the indifferent commercialized principles. Individual and society, individual and nature, individual and others, and even the alienation and confrontation between the individual and self are deepening. The individual is full of loneliness as being ignored and hostile in the society. Even if he is close to others, he seems to be separated by an impenetrable spiritual wall. This kind of indifference and loneliness perfectly describes the futile and meaningless nature of modern life in the novel.

Several characters come to the Garden to wander aimlessly and talk aimlessly. At last, they don't know where to go. The readers can't know their previous life track or infer their future. In the last paragraph, the term "aimless" is used not only to describe the indecision of characters' steps, but also to express their uncertainty about life. Snail is the opposite of human ignorance in the works. Although it is small and slow, it has its own clear goal and keeps trying for it. "The snail seems to have a definite place in mind." "But for it, loose soil, a puddle, a pebble, a large leaf, and a root that is exposed to the ground are all huge obstacles between it and its destination. But the snail never retreated, never hesitated like the thin waisted legs and strange green worms around it." The last description of a snail is this: "The snail has now fully considered: To do not take a detour, and do not climb the dead leaves, there can be some kind of way to reach their destination"? (Woolf, 2015) "Do not say to climb the dead leaves so much effort, look at this thin thing, just take the tip of the tentacles gently touch, Swing for half a day, raucous not scary, is not able to bear their own point of weight, it is a question, so the snail finally decided to climb down, because the dead leaves have a tilted place, higher from the ground, snails completely drilled in" (Woolf, 
2015). In a few words, the psychological world of the little snail is vividly depicted. In fact, it is also a positive energy to convey to readers: the long journey of life is always to achieve different goals and pursue different ideals. We can't change our original mind because of various setbacks and obstacles, but we need to adjust our mentality, slow down our steps, and get closer to the destination in the centrifugation like a small snail in the story.

In Kew Garden, Virginia Woolf changed the traditional narrative style and presented a series of seemingly fragmented plots to the readers with thick strokes. However, the appearance and action of snails in the work successfully connected the four groups of characters into an organic whole. It is not difficult to see that the description of snail in the works has strong symbolic significance, that is, it forms a sharp contrast with the real life and conveys the author's yearning for the ideal life realm in the real life dilemma.

Woolf believes that life is made up of many important moments. Virginia's life is a mixture of success and mental illness. However, as she grew older, her heart became stronger. Although Virginia still experienced pain and sadness, she believes that life will reward everyone at some point. In The Waves, she gave Bernard the task of telling. Bernard suffered from depression when he was young, and had a sensitive and mature mind like Woolf, and carried an ideal of pursuing lasting truth in the novel. When Bernard was old, he looked back on his life, he said, "I then solidified is a man; my vanity was contented, he also confessed, a shell formed a soft soul, glabrous, shiny, feeling in vain to knock on their mouths" (Woolf, 2000). In the process of novel creation, Woolf experienced a period of illness and mental disorder. Her diary describes her mental state, "Wake up, maybe at 3 o'clock. Oh, it's starting--the horror of the body bloated by the heart tossing me ... God, I wish I was dead. Pause. But why would I feel that way? Let me watch the waves rise" (Woolf, 1954). However, she managed to ignore the sad trivia, and she pursued this elusive mentality for the next four years. Before she began to write the first draft, Virginia was deeply depressed. She wrote in his diary: "Lord, how deep it is! As usual, I felt that if I sank further, I would reach the truth. This is the only mitigating measure; a kind of aristocrat. Solemnity. I will put myself in the face of the fact that none of us has anything. Work, reading, writing is all camouflage, and the relationship with people. Yes, even having children is useless ... I'm starting to see ... It's so clear ... My comfort" (Elizabeth, 1993). When she finished reading the last few pages of waves, she was intoxicated. "In any case, it's done" (Bell, 1972). Virginia Woolf realized her important ambition The Waves. She wants to shape her life and give others glory in her novels. The Waves previews the shock of death in the girl's mind. At that moment, she is like a moth flying out of the chrysanthemum. The waves push the dimension of life to the end. Virginia's husband Leonard had a lasting influence on her life. In the spring of 1925, supported by love and friendship, Virginia Woolf finally accepted Toby's death and wrote his elegy, "in this blooming past, when I wrote it, it became sad, beautiful and unforgettable." Her life is full of joy and pain, just like a moth. She finally gave up her life, which 
is undoubtedly a relief for her. All these show the cognitive process of her literary creation.

\section{Conclusion}

Through the analysis of the two animal images of snail and moth in Woolf's novels, we can understand the deep meaning of Woolf s novels, mainly including the social background of the patriarchal society in England at that time, the prevalence of feminism and the androgyny thought in Woolf's novels. Woolf's ecological cognition is based on her close observation of the animals' special biological structure, thus, snail not only performs as the symbol of androgyny, but also as natural harmony and positive meaning of life.

Moths may play a negative role in our daily life, but they play a positive role in Woolf's novels. It is the medium that Woolf used to express her real thoughts, and the moth's life is the real portrayal of Woolf's life.

Moths may change its traditional negative image in our daily life, and form a positive image in Woolf s novels. Therefore, animal images function as the medium for the writers to express their real thoughts. To study the metaphorical images can illustrate the process of cognition during the literary creation, which is a bridge between writer and reader and help to produce a profitable reading outcome. To sum up, the metaphorical reading of the animal images in Virginia Woolf's novels is an effective way to explore her ecological consciousness, thus the interpretation of literary texts under the light of cognitive theory presents a new perspective to the literary study.

\section{Acknowledgements}

This work was supported by Program for Humanities and Social Sciences of Heilongjiang Province (13E050), The Influence of Virginia Woolf s Novels on the Development of British Ecological Literature.

\section{Conflicts of Interest}

The author declares no conflicts of interest regarding the publication of this paper.

\section{References}

Bell, Q. (1972). Virgina Woolf: A Biography. New York: Harcourt, Brace.

Elizabeth, A. (1993). Virginia Woolf and the Fictions of Psychoanalysis. Chicago, IL and London: The University of Chicago Press.

Woolf, V. (1919). The Mark on the Wall. London: Hogarth Press.

Woolf, V. (1954). A Writer's Diary. New York: Harcourt Brace Jovanovich.

Woolf, V. (2000). The Waves. Cody, WY: Wordsworth.

Woolf, V. (2003). The Voyage Out. Fort Washington, PA: Harvest Books.

Woolf, V. (2004). A Room of One's Own. London: Penguin Books Ltd.

Woolf, V. (2015). Short Stories by Virginia Woolf. New York: Urban Romantics. 
Wu, Q. H. (2005). Virginia Woolf and Feminism (pp. 54-156). Beijing: China Social Sciences Press.

Zhang, D. (2015). The World in Snail's Eyes-The Symbolic Meaning of Snails in Kew Garden. Journal of Jiamusi Vocational College, No. 8, 74-75. 